\title{
La naturaleza de la natura: una apunte sobre mística y ciencia en el franciscanismo medieval de la Península Ibérica
}

(Nature of natura: an approach on mystic and science in peninsular Iberian medieval Franciscanism)

\author{
MANUEL LÁZARO PULIDO \\ Universidad Nacional de Educación a Distancia (Madrid, España) \\ Universidad Bernardo O'Higgins (Santiago, Chile)" \\ mlazarop@fsof.uned.es
}

ORCID: 0000-0002-0064-5293

\begin{abstract}
The present paper shows the relationship between the concepts Natura (Latin term, understood as common creatural reality) and Nature (Vernacular term, understood as personal and social reality) at Castillan Court and Franciscan Peninsular thinking on XIII century. Especially we study this distinction in Juan Gil de Zamora wisdom methodology of natural philosophy, equilibrating science, and mystical approach.
\end{abstract}

Keywords: natura; nature; franciscanism; science; secrets.

Trabajo dentro del proyecto de investigación financiado por el Departamento de Ciencias del Derecho de la Universidad Bernardo O’Higgins. 


\section{Introducción}

El estudio de la naturaleza en la Edad Media es un medio fundamental para la comprensión de la realidad creada. La naturaleza creada por Dios adquiere para el logos teológico, basado en la hermenéutica del Logos creador, una unidad no solo subjetivo-especulativa, que era en cierta forma la del filósofo que se enfrentaba a la naturaleza y al cosmos al que él mismo pertenecía y del cual era un todo, a veces como microcosmos, sino que además es alteridad objetiva. De esta forma, la naturaleza entendida como el resultado del acto creador de Dios se asocia, en el siglo XII, a la curiosidad intelectual en un humanismo del microcosmos del hombre creado que va a provocar diferentes formas de pensamiento favorecidas, en el siglo XIII, con la aparición de las órdenes mendicantes y sus diferentes recorridos en la búsqueda del carácter sapiencial del conocimiento.

Los dominicos usan el recurso a la inteligencia y la diligencia en el desarrollo de los saberes; los franciscanos se caracterizan por la espiritualidad de la mística del Cristo pobre y crucificado junto a la contemplación del misterio a partir de la expresión de la belleza de la obra creada. Ambos desarrollan la teología de la imagen y la metafísica del símbolo profundizando, así, el carácter unitario de la naturaleza en la referencia a su propia realidad natural. Coinciden en entender que la naturaleza es creación divina y lugar de estudio intelectual y contemplativo como creación de Dios; la lectura teológica de la naturaleza presenta el dinamismo natural y con ello una posibilidad de considerar las cosas de la naturaleza en su realidad (aunque sea contingente, icónica, y simbólica), en movimiento de pluralidad de seres y ello desde esquemas no exentos de razón, porque eso es la teología, el entendimiento de los presupuestos de la fe y las verdades reveladas de forma racional; pero se trata de una racionalidad con una posibilidad de amplitud hermenéutica, tal como señalara Alano de Lille en sus famosos versos en los que subraya la simbología del mundo vista desde los ojos de la existencia contingente del ser humano: "Omnis mundi creatura, / quasi liber, et pictura / nobis est, et speculum; / nostrae vitae, nostrae mortis, / nostri status, nostrae sortis / fidele signaculum" (Alanus de Insulis 1855, 579B). 
La metáfora de Alano de Lille expresa la relación analógica de semejanza entre libro y naturaleza, libro y salvación, de modo que el libro de la naturaleza (liber naturae) se entiende y se lee como libro salvífico (liber Scripturae), toda vez que es, en realidad, el libro de las creaturas (liber creaturarum). No se trata solo de descubrir la natura entendida como las cosas de la naturaleza, lo que es propio de lo natural (mundo natural) o el de las cosas naturales (mediante la experimentación y la observación de la ciencia); ni la naturaleza de las cosas, la naturaleza de un ser (mediante la investigación de su quidditas et significatio); sino de aunar ambas investigaciones para poder adentrarnos en la naturaleza de la natura: es decir, en la referencia a la naturaleza de modo que las cosas de la naturaleza nos dejen ver la fuente de la naturaleza de las cosas. La naturaleza, en cuanto espacio de lo que nos hace humanos, en cuanto identificación del ser referenciado y que se expresará después en la filosofía y la teología prácticas como ley natural o espacio político (por ejemplo ser natural de algún lugar). Este nexo en el que natura y naturaleza se expresan diferenciadamente, pero de modo correlativo aparece, según algunos autores en Alfonso X, el Sabio (Martin 2008), como puede verse en el título XXIV, Ley I de las Siete partidas (Que quiere decir naturaleza, et qué departimento ha entre natura et naturaleza):

Naturaleza tanto quiere decir como debdo que han los hombres unos con otros por alguna derecha razón en se amar et se querer bien. Et el departimento que ha entre natura et naturaleza es este, que natura es una virtud que face seer todas las cosas en aquel estado que Dios las ordenó: et naturaleza es cosa que semeja á la natura, et que ayuda á seer et mantener todo lo que decende della (Alfonso X 1807, 130).

Para profundizar en esta diferenciación era necesario un entendimiento de la naturaleza (la humanidad en la designación, la referencia humanista y humanizadora) de la natura desde una lectura mística y científica capaz de adentrarse en los secretos de la naturaleza y desvelarlos como referencia al profundo misterio divino. La natura aparece como espacio íntimo de diversas lecturas que permiten descubrir un secreto dispuesto para ser descubierto, en una realimentación constante que hace que la natura que había sido 
objeto de la contemplación teórica vaya siendo objeto de contemplación positiva como algo necesario para la fundamentación racional de la fe, para la propia dignidad humana (y en ella su naturaleza), que se abre paso con la formación del escolasticismo.

Dentro de este abanico de respuestas sobre la naturaleza (natura) los franciscanos manejan unas propias coordenadas que facilitan este despliegue semántico desde su propio desarrollo espiritual e intelectual (forma mentis) y que viene influido por la propia mentalidad del fundador: Francisco de Asís.

Efectivamente, si por algo Francisco de Asís es conocido e, incluso, admirado es por la relación que mantuvo con las criaturas y, en ello, por la lectura que realizó de la naturaleza (natura). Su amor a la naturaleza se basaba en la contemplación de Dios y de Cristo en las criaturas (Schmucki 2000, 67-68). La mirada evangélica sobre la naturaleza cantada por Francisco de Asís, su mirada mística de la naturaleza, supone una invitación al descubrimiento de su significado como imagen de la gracia de la acción divina. Ahora bien a ese descubrimiento que en el Poverello supone el desarrollo del espíritu del "Juglar de Dios” que canta el Misterio (el secreto) que esconde la belleza natural, se le sumará en el desarrollo de la ciencia y la sabiduría franciscana la incorporación de la filosofía natural de Aristóteles. Los franciscanos tienen ante sí el reto de descubrir la naturaleza de la natura desde los presupuestos de la ciencia de Aristóteles (una filosofía de potencia extraordinaria para conocer en su tiempo las cosas de la naturaleza) como uno de los espacios de desvelamiento del vitalismo cosmológico de la mística de la naturaleza cantada por Francisco de Asís, de modo que se pueda profundizar en los dos aspectos fundamentales de la naturaleza de las cosas: su quidditas (su esencialidad) y su significatio (su sacramentalidad). Es decir, salvaguardando en el descubrimiento de la realidad creatural (de la naturaleza) la profundidad de la ley que el hombre descubre en la naturaleza (natura) que es signo y realidad de la expresividad creatural. De la mano de la síntesis de Alejandro de Hales quien "especifica que la ciencia de la sabiduría es la primera, porque, si bien es descubierta después de las otras, las gobierna en cuanto es ciencia que trata de los principios universales del saber” (Felipe 2016, 543), los franciscanos que contemplan esa naturaleza 
no olvidan que son contemplativos, puesto que el hombre es sacramento de contemplación y lo es porque existe una realidad sacramental que lo alimenta. De este modo, el franciscano será consciente de las palabras de Adelardo de Bath en las Quaestiones naturales $(4,64)$ : “Observa atentamente, añade las circunstancias, antepón las causas, y no te sorprenderás de los efectos" (Adelardus Bathensis 1999, 204); pero siempre desde una función metanatural puesto que el efecto es el de la gracia y, por lo tanto, "exige una precisión, un mayor y un cuidado detenimiento en el estudio atento de las circunstancias: la del res y el signum" (Lázaro 2014, 665). Si desde el siglo XIII fue Aristóteles quien proporciona una visión científica del cosmos que hace posible una filosofía de la naturaleza, su irrupción no modificó sustancialmente la concepción cristiana fundada sobre la Creación y sobre la Redención (la profunda humanización de la naturaleza, o dicho de nuestro modo la naturaleza de la natura). Y en este sentido los franciscanos cultivaron el estudio de la naturaleza, profundizándola al ser ella la propia obra creadora de Dios, referencia última del orden cósmico, espacio de alabanza (Cántico de las creaturas). Es el vitalismo cosmológico que se deja ver en los franciscanos de la Península Ibérica en el siglo XIII.

\section{Natura-naturaleza en el franciscanismo peninsular}

En la Corona de Castilla, durante el siglo XIII, especialmente a partir de 1240, se está afianzando el cultivo de las ciencias (Morpurgo 2000). No se trata de un empeño nacido de una forma explícita de la naciente universidad, si bien está inserto en el esfuerzo de la Corte por reavivar el estudio, de crear conocimiento y de difundirlo. Como ha puesto de manifiesto la obra colectiva de Luis García Ballester (García 2002) se trata de un impulso decidido por el estudio y el cultivo del saber. La convicción de la Corona castellana es la de asegurar el estudio de las ciencias como medio de creación de los valores de un periodo que está cambiando, especialmente tras el éxito cristiano en la batalla de las Navas de Tolosa.

Para la nueva situación político-religiosa se necesitan nuevos valores religiosos y de identidad política y para ello es necesario asentar el sustrato 
referencial de la naturaleza (natura-naturaleza) humana en su vertiente horizontal (filosofía de la naturaleza) y vertical (jerarquización del orden natural). Este es el empeño que refleja Alfonso X el Sabio, quien encarnando el modelo platónico de rey filósofo se empeña personalmente en los distintos campos de la cultura (las artes del trívium, quadrivium, derecho, historiografía, teología...) como el lugar de construcción del Estado (Burns 1990). Se trata de una proyección y convergencia peninsular y europea alimentada en la Península por una cierta competitividad identitaria que se refleja en el afán de reconquista entre la Corona de Castilla y la Corona de Aragón, apoyada por las autoridades eclesiásticas que soportan las Coronas en Toledo, Santiago y Tarragona, en sintonía con la autoridad papal de Roma.

En este contexto, las órdenes mendicantes desempeñan un papel vital en el estudio de la naturaleza a través de los studia franciscanos y dominicanos (García 1996, 146), desde donde se impulsarán la elaboración de modelos y arquitectónicas del saber, al estilo de las enciclopedias de su tiempo, y, por lo tanto, en la divulgación de la actividad literaria y científica reflejada en tratados e inserta en los sermones, llegando así a las diferentes realidades sociales y religiosas.

La labor que se realiza sobre la lectura de la naturaleza conoce diferentes aspectos. Por una parte se trata de una observación significativa (quidditativa) y experimental. Entiéndase aquí por experimental lo que la ciencia experimental (scientia experimentalis) significa en su época, en un uso semántico extensivo de experiencia y experimento: si bien para algunos se trata en general de la observación pura y simple poco a poco van separándose los conceptos con entidades conceptuales y semánticas más diferenciadas especialmente en el campo de la investigación biológica, más que en la astronómica. Lo que se puede constatar es que la ciencia experimental va adquiriendo un sentido cada vez más opuesto al razonamiento y a los sistemas racionales (Bénatouïl, Draelants, 2011).

Por otra parte, y junto a la observación, se inicia también una labor de clasificación, recuperando y renovando el espíritu isidoriano (Vollmann 1994) en la nueva construcción del medievo cristiano y occidental que se visualiza en la organización de los saberes, entre ellos los naturales, 
mediante la elaboración de obras enciclopédicas y pedagógicas desde el De floribus rerum naturalium de Arnaldo de Sajonia al Speculum naturale de Vicente de Beauvais. Se trata, pues, del reflejo de un verdadero movimiento de renacimiento no solo en el sentido de la revitalización de los saberes, sino también de la realización de una lectura antropológica a la hora de efectuarlos y abordarlos. Así desde el punto de vista médico se desarrolla una auténtica antropología médica a partir de la antropología cristiana, al punto de que el cristianismo posibilita la antropología médica, al menos como hoy la entendemos. Las imágenes del Dios sanador y del buen samaritano alimentan esta inspiración antropológica en la Edad Media. La llegada de la medicina a las universidades incorporándose al curriculum universitario crea no solo una escuela médica universitaria, y una medicina sometida a la metodología de las Escuelas, sino también la profesionalización del médico y el acceso cada vez más propio del laico a dicha profesión universitaria. Con ello se laiciza también la sabiduría médica y el contexto salvífico de la salud corporal. Sirva esto de paradigma a lo que le sucede a la sabiduría, que vive la tensión del significado simbólico de la hermenéutica de la fe y de su transformación semántica en un primer momento, reduciéndose en su significado a una función racional y metodológica para, en un segundo momento, depender de su propio significado. En este sentido, la reflexión sobre la naturaleza también sufre una dialéctica sobre el despliegue de la observación y de la razón en la comprensión natural tanto del cosmos como del microcosmos, de la naturaleza físico-astronómica y de la biológico-antropológica.

Partiendo de la certeza revelada de que todo tiene su origen en Dios y toda obra creada es signo del Señor, se trata ahora de entender e interpretar los diferentes signos con distintas claves hermenéuticas y metodológicas, diversos planos de comprensión de la realidad en la que la ciencia y la plegaria no impidan ver en sus resultados el acto salvífico. Tanto en ciencia como en filosofía, la lectura naturalista tiene el riesgo de proponerse no solo como lectura interpretativa de los procesos intrínsecos de la creación sino como la única forma de entender los signos de Dios. De esta forma no se pone en duda la existencia de Dios creador ni de la creación, sino que se 
evidencia un cierto (o claro) riesgo de confundir la unificación de las lecturas (teológicas, naturales, físicas y biológicas) a un único fin salvífico y pedagógico del Dios creador, con una unificación reductiva en la que las ciencias naturales terminen siendo el único instrumento válido de comprensión de la naturaleza que Dios ha puesto a disposición del hombre. Se vive así la tensión del propio humanismo propiciado desde la segunda mitad del siglo XII a la segunda mitad del siglo XIII en el que no se olvida el cuadro de referencia de un humanismo cristiano-salvífico, muy adecuado para el plano pastoral y que se refleja en la utilización del conocimiento natural que provoca que estas aproximaciones al conocimiento de la naturaleza tengan una buena acogida no solo escolástica o científica sino, especialmente, en el terreno de la predicación, una circunstancia que además sirvió para “vulgarizar la cultura científica” (Delmas 2017, 10).

En la Península Ibérica no faltan, como en otros lugares geográficos, franciscanos que decidan ahondar en el descubrimiento de la profundidad de la naturaleza creada, desvelar sus secretos y así entender su "naturaleza". Destaca entre ellos Fr. Juan Gil de Zamora (†1311), pero no es el único. Junto a él está quien llegó a ser Obispo de Cartagena tras pasar por Toledo, Fr. Pedro Gallego († 1267). El propio Fr. Juan Gil de Zamora recuerda como Fr. Pedro Gallego fue confesor del hijo de su amigo Fernando III, es decir, del rey Alfonso X en la corte toledana (López 1925, 67) ${ }^{1}$. El ya obispo de Cartagena es autor de una obra sobre economía doméstica titulada De speculatione antecer in regitiva domus, de un tratado de astronomía (De astronomia ) y de un Liber animalibus (Petri Galleci 2000), un tratado de filosofía natural que tiene en cuenta el De animalibus de Aristóteles -que tuvo gran significación como muestran las referencias que hacen de la misma en las obras enciclopédicas (Draelants 1999)- y que probablemente tomó del resumen realizado por Nicolás de Damasco y traducido al árabe, junto a la versión árabo-latina de

\footnotetext{
“Frater Petrus Gallego ingressus est monachus monasterium apud Bastitam Toleti extra civitatem [el convento de la Bastida, a tres kilómetros de Toledo, fundado en 1219] ; succedit in Guardianatu fratri Alphonso Martino, qui misus Toletum anno 1219 fuit primus guardianus [fray Alonso Martín] ; postea anno 1236 era Provincialis [Ministro Provincial de su orden en Castilla], Regi Fernando propter egregias eius virtutes, sanctimoniam et sapientiam nimis charus et filio".
} 
Miguel Escoto y los comentarios y glosas de autores árabes (Pelzer 1924, 436). En este sentido, el autor franciscano muestra un gran conocimiento del pensamiento árabe, reflejo del conocimiento que se tenía en la Península de la filosofía natural árabe, tal como muestra sus referencias a Abu'l-Faray ibn al-Tayyib (m. 10403), utilizado también por el estudioso judío hispano Shem Tob ibn Falaquera (c. 1224-1290), el Epítome de Averroes... (Burnett 2002, 119). El uso de estas fuentes clásicas y greco-árabes, señalan una metodología de utilización de fuentes y autoridades que indican una búsqueda constante de los secretos, de la mística, de la naturaleza del mundo cristiano-latino. Una exploración que está en consonancia con el espíritu de la época de establecer una seria transmisión del conocimiento científico. El franciscano parece, así, empeñado a tenor de sus obras en "difundir entre el gran público europeo cristiano las cuestiones naturales y un acercamiento racional a todos los problemas relacionados con la naturaleza, tanto del propio hombre como del mundo que lo rodeaba” (García 1996, 153).

Estos precedentes son signos de que tenía que circular una significativa variedad de textos de filosofía natural por los conventos y especialmente por los Estudios franciscanos peninsulares de finales del siglo XIII y que tienen como conjunto paradigmático la Historia naturalis de Juan Gil de Zamora (1994), una magna obra de la que conservamos solo hasta el final de la letra A, unos 250 folios de un manuscrito (Ferrero 2010, 21). La intención de acercar el saber que existía en su tiempo planea en todo su esfuerzo como él mismo expone en su proemio al Liber de animalibus.

En este esfuerzo por traer el conocimiento destaca el descubrimiento del mundo natural. Descubrir las formas de realización de la naturaleza, de sus modalidades de actuación, es una tarea difícil, pues implica una visualización de los mecanismos ocultos a la percepción de los datos sensibles proporcionados por los sentidos y porque su complejidad metodológica y conceptual resulta oscura para la mayoría de la población. En este sentido, la ciencia tiene una cierta forma de mística del conocimiento científico en cuanto que la realidad natural implica una lectura de la significación compleja de la naturaleza. En este sentido, el estudio de la naturaleza (natura) determina, a su vez, la naturaleza de aquellos miembros de la sociedad que detentan la 
sabiduría y que pueden tener acceso al conocimiento de ciertos mecanismos y formas de proceder de la naturaleza.

Así, podemos decir que conocer el mundo natural implica "descubrir sus secretos". La ciencia de la naturaleza se relaciona con el descubrimiento de los secretos, de la mirada mística (signficatio) ínsita en su interior. No solo por el propio proceder de la filosofía natural y el carácter secreto que está oculto en la materia, sino porque en la existencia de ese carácter asistían a su desvelamiento otros abordajes herméticos y alquímicos, cuya pretensión no era tanto conocer la naturaleza, cuanto desvelar y manipular su poder oculto (Burnett 2002, 133). No existen pruebas del conocimiento de los textos herméticos en la Corona de Castilla, pero sí de la existencia del interés de la alquimia en Toledo, como lo refleja su inclusión en la filosofía natural por parte de Gundisalvo y Miguel Escoto (Burnett 2002, 131).

Juan Gil de Zamora asiste a este diferente tipo de aproximación al "secreto de la naturaleza” y entiende que puede ser útil acercarse a la naturaleza para conocer su misterio y entender sus formas desde una aproximación de utilidad experimental, como un arte que ayude a la filosofía natural. En este arte es de gran utilidad la obra del Pseudo-Aristóteles (Schmitt, Knox 1985), entonces creída del Estagirita, Secretum secretorum, traducida al castellano y muy vinculada a la Península Ibérica, de modo especial citada por Juan Gil de Zamora y que se conoce como Aristoteles hispanus (Rico, 1967). Esta obra conocida en Occidente (Williams, 1994), tiene una repercusión especial en la Corona de Castilla, siendo la primera obra traducida vinculada a Aristóteles y de gran circulación entre los colaboradores del scriptorium alfonsí. De hecho es citada por el propio fraile franciscano bajo el nombre de De ingenio regni (y sus variaciones: De ingenio regiminis, De ordinationi ingenii regni, De ingenio ordinationis regni). El Secreto de los secretos tiene un tono de gran influencia en el pensamiento político y se deja sentir en el franciscano especialmente en su obra De preconiis Hispaniae ( Iohannis Aegidii Zamorensis 1995, clxxxiii). El fraile franciscano posiblemente no solo conocía la traducción castellana sino también la versión latina en su estancia de estudios en París. 
Juan Gil de Zamora incluye en el De preconiis referencias del Secretum relativas a la astronomía. El Secreto de los secretos mantenía una mirada de la naturaleza que alentaba la via experimentalis frente a la via rationis como mejor método de comprensión de la Naturaleza en la que se empeñan las ciencias (Barnett 2002, 133). De este modo, Juan Gil de Zamora parece moverse por los terrenos de la explicación de la naturaleza (natura) en el intento de racionalizar los fenómenos, pero no mirando hacia atrás en el tiempo, sino proyectando la tradición en un presente, de modo que la nueva naturaleza del hombre castellano sea capaz de penetrar la esencia de la natura. Así, su Historia naturalis recuerda a la tradición isidoriana de la explicación alegórica. Es decir, la lectura científica de la naturaleza no puede olvidar su lectura mística (significativa) si se quiere conocer su auténtica significación. Como buen franciscano recupera la exégesis natural (que hemos señalado en los versos de Alano de Lille) donde la naturaleza aparece como un libro que nos muestra la presencia de Dios y que como la propia palabra revelada (la Biblia) es susceptible de recibir una lectura literal y simbólica. La ciencia y la mística de la naturaleza cooperan en aras a una contemplación de la sabiduría (donde se suma la ciencia y la teología); de ahí "que la contemplación de las cosas naturales sea, ante todo, desvelación de los símbolos contenidos en ellas" (García, Domínguez 1994, 267). La empresa intelectual de fray Juan Gil de Zamora supone un acercamiento a la naturaleza que no olvida el espíritu de mostración de la naturaleza como libro de la creación divina.

La activación de las lecturas cooperantes de la naturaleza se da especialmente en el Reino de Castilla, a través de los franciscanos, que no recelaron de los estudios (Rucquoi 1996, 71). Los franciscanos castellanos (no exclusivamente) supieron ver que el estudio sapiencial (ciencia y mística) de la natura hecha desde una forma mentis franciscana contribuía a modelar la naturaleza humana que configura la comunidad humana. De este modo, el estudios de los secretos de la naturaleza (natura) es un modo privilegiado de realizar el fin principal que no es otro que seguir a Cristo pobre y crucificado, orando y predicando la conversión. La lectura del libro de la naturaleza en los franciscanos mantiene así un tono misionero y de espíritu franciscano 
que refleja a su vez, las tensiones internas existentes entre el modelo de vivir franciscanamente propuesto por conventuales y espirituales. Los estudios sitúan a Juan Gil de Zamora más próximo a la línea crítica, es decir, la espiritual, como podría interpretarse de la dedicación de la obra Liber contra uenena a Raymundo de Geoffroi, cuyo generalato estaba próximo a la corriente espiritual. Se trataría de una alineamiento cercano al que había hecho Pedro de Juan Olivi quien sin seguir los pasos de un intelectual su pensamiento sí que supo leer, a su manera radical, aquellos consejos dados por el maestro Buenaventura en sus obras como el De reductione artium ad theologiam, en el que se presentaba una visión sapiencial que supiera equilibrar la formación y la búsqueda de la verdad con la iluminación. Juan Gil de Zamora, al modo de Olivi, sabe equilibrar el aristotelismo con la fe teológica, a través de una vía alejada del intelectualismo que representa Aristóteles y asumiendo junto a la filosofía natural (la ciencia) la ayuda inequívoca de la iluminación divina (mística). Juan Gil de Zamora, así se servirá de la filosofía natural de Aristóteles como herramienta intelectual y metodológica útil para comprender la naturaleza, pero siempre desde el modelo hermenéutico sapiencial que supone la apuesta por la riqueza expresiva del libro de la naturaleza que nos lleva al misterio de Dios con el auxilio de la iluminación divina. El descubrimiento de los secretos de la naturaleza conduce a quien se acerca a ella a la búsqueda de lo alto.

La metáfora que utiliza para hablar de la sabiduría, encarnada en san Francisco, tiene como antecedente la autoridad de san Antonio de Lisboa/ Padua en su Expositio mystica in librum Apocalypsis cap. XII: Aquila et accipiter in hoc loco uirum iustum significant. Se trata de la famosa imagen del azor que reproduce Fr. Juan Gil de Zamora:

En virtud de estas características, nuestro santísimo padre Francisco puede compararse con el azor, porque fue muy severo con sus hermanos gracias a la institución de una orden severa; fue como una medicina para ellos mediante la observancia de nuestra santa profesión; fue como un ave de presa, cuando convertía a los hombres gracias a la eficacia de su predicación; le apetecía también a él la carne fresca y lamía la sangre, cuando meditaba continuamente la pasión del Señor. En virtud de todo esto, queriendo Dios que San Francisco 
y sus hijos no fueran destruidos por la jerarquía eclesiástica, ni comidos, ni aniquilados, sino amados y favorecidos, por esto dice: Éstas son las aves, es decir los religiosos preocupados por las cosas celestes, que no deben ser devoradas. (Johannes Aegidius Zamorensis 1994, 219).

La figura del azor es un signo más de los que supone el conocimiento sapiencial de la naturaleza (natura) para la naturaleza humana. El azor representa una sabiduría, no solo intelectual sino también moral. Su imagen moralizante supone mostrar que el estudio y el desvelamiento de los secretos de la natura nos lleva a la configuración moral (y socio-política) humana (de su naturaleza). El conocimiento (científico-místico) se al servicio de la acción pastoral (práctica). Descubrir los secretos de la naturaleza, que proclaman la gracia de Dios, impiden poner el conocimiento de un poder oculto al servicio de los propios intereses. La dualidad natura-naturaleza desde la visión sapiencial de acceso al conocimiento (ciencia-mística) fortalecen la vocación de servicio del conocimiento; y, por otra parte, favorece la trasmisión del mismo en cuanto que puede usarse en diversos niveles nacidos del lenguaje científico (para la comunidad de los sabios) y de un lenguaje alegórica (puesta al servicio de la comunidad en general) sin caer en dicotomía. La natura es un espacio de configuración social y humana (naturaleza) como lo señala su utilización en la predicación (Díez 2015), pues la naturaleza proclama la gracia de Dios Creador. Así se entiende que Juan Gil de Zamora habla en su Historia naturalis de las virtudes contemplativas del conocimiento de las cualidades, potencias y virtudes de las cosas -sus sabores y olores $-^{2}$. Apoyado en las citas da autoridad realiza una breve interpretación moral del algún rasgo sobresaliente de la naturaleza que nos ayuda en la configuración moral-evangélica de nuestra naturaleza (Martínez $1998,180)$. Pero no solo este acercamiento sirve para configurar la natura de la comunidad en general, sino de la propia comunidad científica, toda vez que invita a quien busca en la naturaleza a no desatender su utilidad práctica sea personal (contemplativa), sea comunitaria (pastoral).

2 “[...] per qualitates rerum et colores et sapores et odores et potencias et uirtutes sapiens poterit Altissimum contemplari”. (Johannes Aegidius Zamorensis 1994, 124). 
Esta prevención no solo atiende a no caer en la realización de una ciencia sin sapiencia, sino también a evitar una ciencia sin conciencia en la que se quiera utilizar una lectura de la naturaleza que pueda estar tentada en por la alquimia o la magia (Lucentini 2000; Boudet 2006). Una búsqueda que tiene como fin la utilización del poder tanto en la lectura de las propiedades de la naturaleza como del conocimiento en sí, que provoca afirmar a Fr. Juan Gil de Zamora que no pocas veces "buscar y conocer las cosas terrenas es vicio carnal del alma” (García, Domínguez 1994, 263). No es malo penetrar en las cosas visibles, en la natura, puesto que Dios invisible se manifiesta en ella. Ya san Buenaventura había puesto ejemplo metafísico-estético en sus tratados teológicos (especialmente en el Itinerarium mentis in Deum (Lázaro 2005) y en la propia Leyenda mayor (Lázaro 1997) de ello. Por este motivo, Juan Gil de Zamora se acerca a la filosofía natural consciente de que el estudio de la naturaleza moldea la naturaleza humana y su cosmovisión cristiana. El hombre que se acerca racionalmente a la naturaleza es consciente de que en ella se revela la gracia del poder de Dios. La naturaleza es espacio visible de la sabiduría y bondad de Dios. Por eso en su Historia natural o de la naturaleza de las cosas (Historia Naturalis siue De rerum natura), Dios es definido como natura naturans (deus altissimus et eternus) que muestra entre sus secretísimas causas las naturas naturatas ${ }^{3}$.

El descubrimiento de los secretos de la naturaleza, de su quidditas y de su significatio, desde la filosofía natural y desde la hermenéutica de la iluminación (mística) en el pensamiento franciscano ibérico, reflejado de forma magisterial en fray Juan Gil de Zamora, representa un último ensayo por realizar un acercamiento equilibrado entre el vitalismo natural del espíritu de san Francisco de Asís y la filosofía natural aristotélica. Este equilibrio no era fácil, pero era necesario. El entorno filosófico-teológico desencadenado tras las condenas de 1277 exigía superar la tensión vivida a nivel doctrinal-académico. Esta tensión tenía un tenor especial dentro de la Orden debido al intenso debate entre espirituales y conventuales y que encontraba en el significado del estudio un topos paradigmático. Junto a estas circunstancias generales al mundo académico (1277) y franciscano

3 MS Berlin SB, lat Fol. 62 (XIV) fol. 1r. (Reinhardt, Santiago-Otero 1986, 201). 
(observantes-celantes), se le suma la pugna en el Reino de Castilla por la significación del estudio de la naturaleza (natura, en latín quizás para expresar la universalidad del concepto natural) como espacio de construcción de la naturaleza del nuevo hombre de Castilla y que se visualiza en la pugna entre la filosofía natural aristotélica y la necromancia hermética como medios para obtener un conocimiento de los secretos del universo (Burnett 2002, 139).

La figura del maestro franciscano Juan Gil de Zamora nos sirve como modelo de equilibrio de las tendencias presentes de modo que es capaz de equilibrar el valor del conocimiento de la filosofía natural aristotélica en cuanto método racional (evitando caer en la magia) abierta a la ayuda de los saberes secretos (manteniendo el gusto de la Corona de Castilla). Ciencia y mística al servicio de la comprensión de una naturaleza que sin olvidar su orientación última, su referencia al Creador y su significado en cuanto naturaleza creada de ser expresión del último misterio y realidad fundante de toda natura -Dios creador- (agustinismo), está puesta al servicio de la realización práctica (didáctico-pastoral), de la configuración de la naturaleza. Natura, en latín quizás para expresar la universalidad del concepto natural y naturaleza en castellano, quizás para mostrar la carta de construcción humana en un contexto social, jurídico y político.

En fin, un marco de referencia de la labor científico-jurídica de la Corte de Alfonso X el Sabio, y de la constitución de un nuevo y definitivo marco de relaciones sociales en el territorio peninsular cristiano y eliminar que ha señalado el acontecimiento decisivo de la Batalla de las Navas de Tolosa; relaciones basadas en la profundidad sapiencial de la natura humana como había manifestado san Buenaventura en relación al dominio de la naturaleza humana manifestado en san Francisco donde "la austeridad de la vida, seguida del consuelo de la naturaleza se inscribe en el primer paso efectivo del Itinerario hacia Dios” (Lázaro 2016, 210).

\section{Referencias}

Adelardus Bathensis. 1999. "Quaestiones naturales." In Adelard of Bath, Conversations with His Nephew: On the Same and the Different, Questions on Natural Science and On Birds, edited by Charles Burnett, With the collaboration of Italo Ronca, 
Pedro Mantas España, and Baudouin van den Abeele. Cambridge: Cambridge University Press.

Aegidius Zamorensis, Johannes. 1994. Historia naturalis. Edited by A. Domínguez,

L. García. Valladolid: Consejería de Cultura y Turismo. Junta de Castilla y León. Aegidius Zamorensis, Johannes. 1995. De preconiis Hispaniae. Edited by Manuel de Castro, Madrid: Universidad Complutense.

Alanus de Insulis. 1855. “De Incarnatione Chisti. Rhythmus perelegans.” In Patrologiae cursus completus. Series Latina, in qua prodeunt Patres, doctores scriptoresque Ecclesiae Latinae, a Tertulliano ad Innocentium III, edited by Jacques-Paul Migne, vol. 210, col. 579B. Paris: s.n.

Alfonso X. El Sabio. 1807. Las Siete Partidas del Rey Don Alfonso X, el Sabio, 3. Madrid: Imprenta Real.

Bénatouill, Thomas, Draelants, Isabelle, ed. 2011. Expertus sum. L'expérience par les sens dans la philosophie naturelle médiévale. Actes du colloque international de Pont-à-Mousson, 5-7 février 2009. Firenze: SISMEL, Edizioni del Galluzzo.

Boudet, Jean-Patrice. 2006. Entre science et «nigromance». Astrologie, divination et magie dans l'Occident médiéval (XIIe-Xve siècles). Paris: Publications de la Sorbonne.

Burnett, Charles. 2002. “Filosofía natural, secretos y magia.” In Historia de la ciencia y de la técnica en la Corona de Castilla. I Edad Media. Edited by L. García. 95-144. Salamanca: Consejería de Educación y Cultura. Junta de Castilla y León.

Burns, Robert I. ed. 1990. Emperor of Culture. Alfonso X the Learned of Castile and His Thirteenth-Century Renaissance. Philadelphia: University of Pennsylvania Press.

Delmas, Sophie. 2017. "La réception des encyclopédies naturelles dans les sermons au XIIIe siècle. Quelques exemples.” Rursus-Spicae 11. Accessed January 06, 2018. doi: 10.4000/rursus.1340.

Diez, María del Carmen. 2015. “Lenguajes de la evangelización en la cultura popular. Los lenguajes del franciscanismo.” Cauriensia 10: 67-90.

Draelants, Isabelle. 1999. "La transmission du De animalibus d'Aristote dans le De floribus rerum naturalium d'Arnoldus Saxo.” In Aristotle's Animals in the Middle Ages and Renaissance. Edited by C. Steel, G. Guldentops, P. Beullens. 126-58. Leuven: Leuven Univesity Press.

Felipe, José María. 2016. "El orden de las ciencias especulativas concebido por Alejandro de Hales según su Comentario a la metafísica aristotélica." Cauriensia 11: 531-44.

Ferrero, Carmen. 2010. “Nuevas perspectivas sobre Juan Gil de Zamora.” Studia Zamorensia 9: 19-33. 
García, Luis. 1996. “Naturaleza y ciencia en la Castilla del siglo XIII. Los orígenes de una tradición: Los Studia franciscano y dominico de Santiago de Compostela (1222-1230).” In VI Semana de Estudios Medievales: Nájera, 31 de julio al 4 de agosto de 1995. Edited by José Ignacio de la Iglesia Duarte, Francisco Javier García Turza, José Ángel García de Cortázar, 145-70. Logroño: Instituto de Estudios Riojanos.

García, Luis, Domínguez, Adelino. 1994. “El mundo médico de la Historia naturalis (ca. 1275-1296) de Juan Gil de Zamora.” Dynamis. Acta Hispanica ad Medicinae Scientiarumque Historiam Illustrandam 14: 249-68.

Galleci, Petri. 2000. Opera omnia quae extant: De astronomia. Liber de animalibus, De regitiua domus. Edited by J. Martínez. Firenze: SISMEL, Edizioni del Galluzzo.

García, Luis, ed. 2002. Historia de la ciencia y de la técnica en la Corona de Castilla. I Edad Media. Salamanca: Consejería de Educación y Cultura. Junta de Castilla y León.

Lázaro, Manuel. 1997. “La cosmología bonaventuriana: visión franciscana del hombre y del mundo." Naturaleza y gracia 44: 68-95.

Lázaro, Manuel. 2005. La creación en Buenaventura: acercamiento filosófico a la metafísica expresiva del ser finito. Grotaferrata (Roma): Frati Editori di Quaracchi.

Lázaro, Manuel. 2014. “'Theologia magistra philosophiae'. Un ejemplo: la lectura teológica de la naturaleza y el naturalismo filosófico en el siglo XII.” Anuario Filosófico 47 (3): 643-65.

Lázaro, Manuel. 2016. “Bases del uso, dominio y propiedad en la escuela franciscana: la relación con la realidad creada en el Francisco de Buenaventura.” Cauriensia 11: 197-220.

López, Anastasio. 1925. “Fr. Pedro Gallego, primer Obispo de Cartagena (1250-1267).” Archivo Iberoamericano XII: 65-91.

Lucentini, Paolo. 2000. “L'ermetismo magico nel secolo XIII.” In Sic itur ad astra. Studien zur Geschichte der Mathematik und Naturwissenschaften. Festschrift für des Arabisten Paul Kunitzsch zum 70. Geburtstag. Edited by M. Folkerts, R. Lorch. 409-50. Wiesbaden: Harrassowitz.

Martin, Georges. 2008. "Le concept de « naturalité » (naturaleza) dans les Sept parties, d’Alphonse X le Sage.” e-Spania. Accessed January 06, 2018. doi:10.4000/espania. 10753.

Martínez, José. 1998. “Moralización de las piedras preciosas en la Historia Naturalis de Juan Gil de Zamora (1240-1320).” Faventia 20(2): 177-86.

Morpurgo, Piero. 2000. L'armonia dela natura e l'ordine dei governi (secoli XII-XIV). Firenze: SISMEL, Edizioni del Galluzzo. 
Pelzer, Auguste. 1924. "Un traducteur inconnu: Pedro Gallego, Franciscain et premier évêque de Carthagène (1250-1267).” In Miscellanea Francesco Ehrle: Scritti di storia e paleografia, vol. I. 407-56. Ciudad del Vaticano: Biblioteca Apostólica Vaticana.

Reinhardt, Klaus, Santiago-Otero, Horacio. 1986. Biblioteca bíblica ibérica medieval. Madrid: CSIC.

Rico, Francisco. 1967. "Aristoteles Hispanus. En torno a Gil de Zamora. Petrarca y Juan de Mena.” Italia Medioevale e Umanistica 10: 143-164.

Rucquoi, Adeline. 1996. “Los franciscanos en el Reino de Castilla.” In VI Semana de Estudios Medievales. Nájera, 31 de julio al 4 de agosto de 1995. Edited by J. I. de la Iglesia, J. García, J. A. García de Cortázar. 65-86. Logroño: Gobierno de la Rioja, Instituto de Estudios Riojanos.

Schmitt, Charles B., Knox, Dilwyn. 1985. Pseudo. Aristoteles Latinus. A guide to latin works falsely attribued to aristotle before 1500. London: The Warburg Institute.

Schmucki, Oktavian. 2000. “Die Naturmystik des hl. Franziskus von Assisi.” Vita Fratrum 1: 67-77.

Vollmann, Benedikt Konrad. 1994. "La vitalità delle enciclopedie di scienza naturale: Isidoro di Siviglia, Tommaso di Cantimpré, e le redazioni del cosddetto ‘Tommaso III'.” In L'enciclopedismo medievale, edited by Michelangelo Picone, 135-45. Ravenna: Longo Editore.

Williams, Steven J. 1994. "The early circulation of the Pseudo-Aristotelian 'Secret of Secrets' in the West: the Papal and Imperial Courts.” Micrologus 2: 127-124. 